\title{
Knee osteoarthritis and perceived social support amongst patients in a family medicine clinic
}

\author{
Temitope Iloria* (D), Modupe M Ladipo ${ }^{a}$, Adetola M Ogunbode ${ }^{b}$ and Abimbola M Obimakinde ${ }^{a}$ \\ a Department of Preventive Medicine and Primary Care, College of Medicine, University of Ibadan, Ibadan, Nigeria \\ ${ }^{b}$ Department of Family Medicine, University College Hospital, Ibadan, Nigeria \\ *Corresponding author, email:boatop@yahoo.com
}

\begin{abstract}
Background: Knee osteoarthritis is a chronic disease affecting the lives of patients and their families, with the family characteristics moderating the illness course. The perceived social support received by a patient helps in determining the health and functionality of the patient.

Methods: A cross-sectional study was undertaken of 270 patients with knee osteoarthritis attending a family medicine clinic between January and March 2011. The socio-economic and family characteristics of the respondents were obtained. The Multidimensional Scale of Perceived Social Support (MPSS) was used to assess perceived social support by the respondents, while functional health was assessed using the Ibadan Knee/Hip Osteoarthritis Measure (IKHOAM).

Results: The majority (68.8\%) of the respondents perceived an adequate level of social support from their family members, majorly from their children. Individuals who perceived strong support from their family (69.9\%) and friends (71.6\%) had a good health perception at a $p$-value of 0.002 and 0.037 respectively. The study also showed a statistically significant association between strong perceived family support and high functional health status $(p=0.000)$.

Conclusions: The health perception of patients and their physical functionality was positively associated with strong perceived family support. Families and friends can be effective sources of social support for patients with knee osteoarthritis, which help to promote their health outcomes.
\end{abstract}

Keywords: family support, functional health, health status, knee osteoarthritis, perceived social support

\begin{abstract}
Introduction
Knee osteoarthritis is a chronic, degenerative disorder of multifactorial aetiology, characterised by pain, inflammation and stiffness due to loss of articular cartilage, periarticular bone and soft tissue remodelling. ${ }^{1,2}$ In humans, the knee supports nearly the whole weight of the body, making it the joint that is most vulnerable to the development of osteoarthritis. ${ }^{2}$ Knee osteoarthritis is strongly correlated with ageing with a rising prevalence with advancing age..$^{1,2}$ Worldwide estimates are that $9.6 \%$ of men and $18.0 \%$ of women aged 60 years and older have symptomatic osteoarthritis. ${ }^{3}$ In Nigeria, one out of every five adults aged 40 years and older has symptomatic knee osteoarthritis with a point prevalence of $19.6 \% .{ }^{4}$ Globally, there is a female preponderance for knee osteoarthritis. ${ }^{3-5}$
\end{abstract}

Osteoarthritis of the knee is one of the leading causes of global disability. ${ }^{5}$ Ogunbode et al. in 2014 reported that knee osteoarthritis significantly impaired the health and daily activities of adult patients in Ibadan, Nigeria. ${ }^{6}$ Guidelines published by the American College of Rheumatology Diagnostic and Therapeutic Criteria Committee provide the classification of osteoarthritis as a clinical syndrome in older adults who present with joint pain, tenderness, limitation of movement, early morning stiffness and joint crepitus. ${ }^{8}$ In clinical practice the diagnosis of knee osteoarthritis is often made on the basis of history and physical examination. ${ }^{1,8}$

Knee osteoarthritis is a chronic illness that affects the patient, with the family as a primary source of support. ${ }^{9}$ The structure and quality of the family relationship can influence what chronically ill patients do to manage their illness as well as how they perceive their physical, mental and emotional health. ${ }^{10-12}$

Marriage is an example of a socially defined structure that has long been linked with health and illness; for instance married adults have a lower prevalence of illness and are more likely to recover faster than unmarried adults. ${ }^{13}$ Social support can be defined as those social interactions or relationships that provide individuals with the actual assistance or a feeling of attachment to a person or group that is perceived as caring or loving. ${ }^{12,13}$ The benefits that people may receive from their personal network could be emotional, instrumental, informational or appraisal support. ${ }^{14}$ Research has shown that individuals who have a strong social network live longer than socially isolated people. ${ }^{15-17}$ Chronic illness in a family member can cause emotional distress throughout the family and may impair the family's ability to support the patient. ${ }^{15,16}$ The pain experienced by patients with knee osteoarthritis sometimes acts as a mechanism regulating the relationship among family members. Studies have shown that better understanding among family members enhances relationship leading to better health outcomes. ${ }^{15,18,19}$

It has been well documented in the literature that selfassessment is a good indicator of an individual's actual physical status. $^{20,21}$ There are many sources of support, which include the person's spouse, family members, friends, co-workers or physicians, hence Zimet et al. measured social support in three domains namely family, friends and significant others. ${ }^{21}$ The structural components of social support such as marital or relationship status, and the number of children, appear to have a 
direct effect on health whereas functional or perceived social support (such as quality of relationships) indirectly affects health by buffering stress. ${ }^{22,23}$

This study assessed the perceived family and social support and its health impact on patients with knee osteoarthritis who presented to a family medicine practice. The family physician as the first-choice provider of health care, understanding how the family influences health, has the opportunity to utilise the family as a resource in caring for these patients.

\section{Methods \\ Study design}

This cross-sectional study was conducted at the Family Medicine Clinic of the University College Hospital (UCH), Ibadan. Ibadan, the capital of Oyo state, is the largest city in West Africa and is located in the south-western part of Nigeria with a population of 2.55 million people. ${ }^{24}$ The clinic primarily serves an ethnically diverse lower and middle-income population, offering primary and secondary levels of care in a tertiary hospital. Patients with chronic diseases obtain longitudinal health care services within the clinic and are referred to other specialists as the need arises.

\section{Study population}

The study population consisted of 270 adult patients (18 years and above) with knee pain who presented at the Family Medicine Clinic between January and March 2011. Adult patients with knee pain were screened; 270 consenting patients who met the American College of Rheumatology (ACR) clinical diagnostic criteria for knee osteoarthritis were recruited consecutively into the study until the sample size was attained. The Leslie and Kish formula for single proportion ${ }^{25}$ was used to calculate the sample size using the $19.6 \%$ prevalence of adult Nigerians with knee osteoarthritis. ${ }^{3}$

\section{Instruments}

Respondents were screened with the Knee Pain Screening Tool (KNEST). This was an instrument from previous standardised research. ${ }^{26}$ The KNEST is a simple tool for the identification of individuals with knee pain as the starting point for diagnosing knee osteoarthritis. ${ }^{26} \mathrm{~A}$ detailed history and comprehensive knee examination of the respondents was conducted by the researchers and the ACR criteria were used to diagnose knee osteoarthritis clinically. ${ }^{7}$ Radiographs of the knee(s) were requested to confirm the diagnosis. Those that fulfilled the clinical criteria were further interviewed with a semi-structured pre-tested questionnaire to obtain their socio-economic and family characteristics, perceived social support and their functional health status.

The Multidimensional scale of Perceived Social Support (MPSS) by Zimet et al. ${ }^{21}$ was used to assess perceived social support as perceived by the respondents from family, friends and significant others. The MPSS is a subjective assessment of social support adequacy and is a 12-item, 5-point Likert scale, validated in various groups and countries including Nigeria with good internal consistency. ${ }^{21}$ A mean score greater than 3 for each subscale denotes good perceived social support in that subscale. Higher scores indicate higher levels of perceived social support.

The functional physical health status was assessed using the Ibadan Knee/Hip Osteoarthritis Measure (IKHOAM). ${ }^{28}$ This is a disease-specific, three part, 33-item instrument that has been validated with internal consistency and sensitivity and recommended for use in individuals with knee osteoarthritis in Nigerian clinical settings and similar environments. ${ }^{27,28} \mathrm{~A}$ mean score greater than 50 denotes high functional health status. The validated Yoruba Version of the IKHOAM developed to encourage its use in the south-western region of Nigeria where this study was conducted was also used. ${ }^{29}$

\section{Data analysis}

Information obtained was entered into SPSS ${ }^{\circledR}$ version 16 (SPSS Inc., Chicago, IL, USA) and analysed with frequency for categorical variables, and mean and standard deviation for continuous variables. Chi-square statistics was used to measure associations with a $p$-value $<0.05$ accepted as significant.

\section{Ethical considerations}

Ethical clearance for the study was obtained from the joint University of Ibadan/University College Hospital Ethical Committee (UI/UCH EC with Registration Number NHREC/05/01/2008a). Departmental approval from the Head of Family Medicine Department was also sought. Informed consent was obtained and obtained from each study respondent recruited in accordance with ethical principles for the guidance of physicians in medical research.

\section{Results}

Socio-economic and family characteristics of respondents A total of 173 (64.1\%) of the respondents were married, 146 $(54.1 \%)$ respondents were in a polygamous type of marriage and the majority of the respondents 169 (62.6\%) had an extended family unit.

The ages of the respondents' first child ranged from 1 year to 68 years with a mean age of $37.97 \pm 12.00$ years. Half of the respondents 139 (51.5\%) had between three and five children alive at the time of study.

In all, 109 (40.4\%) lived with a spouse and children, 60 (22.2\%) lived with an adult child, while 21 (7.8\%) lived with other extended family members as shown in Table 1 . The mean monthly income for the study population was $24819 \pm 29645$ naira, with a range of 3000 to 250000 naira. Most of the respondents $(254 ; 94.1 \%)$ earned more than a dollar a day. One dollar equalled 150 naira at the time of the study.

\section{Sources of perceived family support}

Most respondents $186(68.8 \%)$ indicated that their source of family support was from their children. This is shown in Figure 1.

\section{Family and social support and health perception}

The three subscales of family, friends and significant others are shown in Table 2. 
Table 1: Socio-economic and family characteristics of the respondents

\begin{tabular}{|c|c|c|}
\hline Family setting & Frequency & Percentage (\%) \\
\hline \multicolumn{3}{|l|}{ Marital status } \\
\hline Married & 173 & 64.1 \\
\hline Single & 4 & 1.4 \\
\hline Divorced & 1 & 0.4 \\
\hline Separated & 3 & 1.1 \\
\hline Widowed & 89 & 33.0 \\
\hline \multicolumn{3}{|l|}{ Type of marriage } \\
\hline Monogamous & 124 & 45.9 \\
\hline Polygamous & 146 & 54.1 \\
\hline \multicolumn{3}{|l|}{ Type of family unit } \\
\hline Nuclear & 101 & 37.4 \\
\hline Extended & 169 & 62.6 \\
\hline \multicolumn{3}{|l|}{ Number of children alive } \\
\hline Nil & 4 & 1.5 \\
\hline $1-2$ & 28 & 10.4 \\
\hline $3-5$ & 139 & 51.5 \\
\hline$>5$ & 99 & 36.6 \\
\hline \multicolumn{3}{|l|}{ Living arrangements } \\
\hline Lived alone & 34 & 12.6 \\
\hline Lived with spouse only & 41 & 15.2 \\
\hline Lived with spouse and children & 109 & 40.4 \\
\hline Lived with parent(s) & 2 & 0.7 \\
\hline Lived with adult child & 60 & 22.2 \\
\hline Lived with sibling(s) & 3 & 1.1 \\
\hline $\begin{array}{l}\text { Lived with other extended } \\
\text { family members }\end{array}$ & 21 & 7.8 \\
\hline \multicolumn{3}{|l|}{ Income } \\
\hline Below poverty line & 16 & 5.9 \\
\hline Above poverty line & 254 & 94.1 \\
\hline Total & 270 & 100 \\
\hline
\end{tabular}

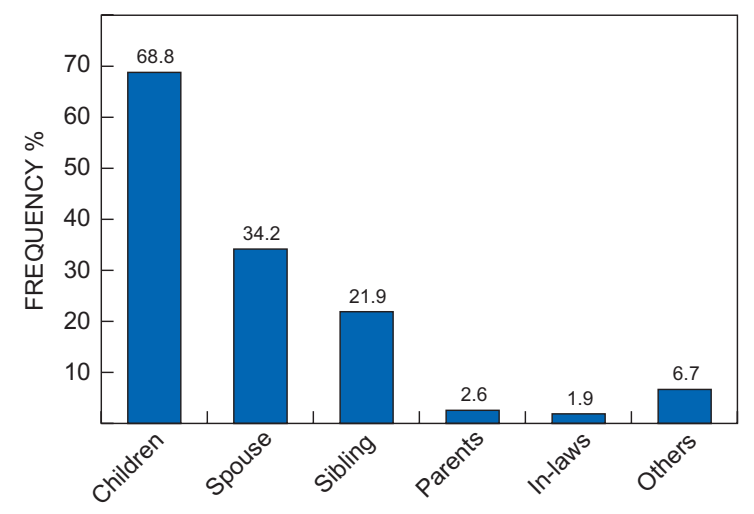

Figure 1: Bar chart showing the source of perceived family support.
Table 2: Frequency distribution of family and social support (using MPSS) in relation to perceived health status of the respondents

\begin{tabular}{|c|c|c|c|c|}
\hline $\begin{array}{l}\text { Family and } \\
\text { social support }\end{array}$ & $\begin{array}{c}\text { Good health } \\
\text { perception, } \boldsymbol{n} \\
(\%)\end{array}$ & $\begin{array}{l}\text { Poor health } \\
\text { perception, } n \\
(\%)\end{array}$ & $\chi^{2}$ & $p$-value \\
\hline \multicolumn{5}{|c|}{ Support from family } \\
\hline Strong support & $153(69.9)$ & $66(30.1)$ & 9.527 & $0.002^{*}$ \\
\hline Weak support & $24(47.1)$ & $27(52.9)$ & & \\
\hline \multicolumn{5}{|c|}{ Support from friends } \\
\hline Strong support & $96(71.6)$ & $38(28.4)$ & 4.364 & $0.037^{*}$ \\
\hline Weak support & $81(59.6)$ & $55(40.4)$ & & \\
\hline \multicolumn{5}{|c|}{ Support from significant others } \\
\hline Strong support & $75(63.0)$ & $44(37.0)$ & 0.603 & 0.437 \\
\hline Weak support & $102(67.5)$ & 49 (32.5) & & \\
\hline
\end{tabular}

*Statistically Significant at $5 \%$ level of significance.

More respondents $(153 ; 69.9 \%$, and $96 ; 71.6 \%)$ with strong support from their family and friends respectively had good health perception. There was a statistically significant association between strong support from family and friends and good health perception ( $p=0.002$ and 0.037 ) respectively.

\section{Family and social support and functional health}

A greater proportion of respondents $(188 ; 92.2 \%, 175 ; 85.4 \%$, and $146 ; 72.6 \%$ ) with strong support from their family, friends and significant others respectively had high functional health status. There was a statistically significant association between strong support from family, friends and significant others with high functional health status $(p=0.000)$. This is shown in Table 3.

\section{Discussion \\ Family demographics and support system}

A higher proportion of the respondents were married. This marital characteristic is significant in affecting an individual's perception of family support, since support from a spouse is considered one of the most important sources of support during illness episodes. ${ }^{22}$ Most respondents studied were in polygamous marriages, which is a reflection of the culture with polygamy being a common practice in Nigeria. ${ }^{10}$

More of the respondents lived in extended family units. In Africa, high values are placed on kinship ties with extended families found to be the traditional social-welfare security. ${ }^{23} \mathrm{Mba}$ in 2007 reported that West Africa showcased the family as a key institution for elderly persons and their living arrangements are a fundamental determinant of their well-being. ${ }^{23}$ In the respondents studied, family support played an important role in moderating the effects of pain and functional limitation. There was a significant positive correlation between family support and functional health in this study: those with good family support scores tended to have higher functional health scores, translating into better physical functioning. This finding is supported by a systematic review, which identified social support as a possible factor that influences physical activity in patients with knee osteoarthritis. ${ }^{30}$ Other studies have also reported the family as 
Table 3: Association of family and social support in relation to functional health status of respondents

\begin{tabular}{|c|c|c|c|c|c|}
\hline Family and social support & Low functional health, $\boldsymbol{n}(\%)$ & High functional health, $\boldsymbol{n}(\%)$ & Total $n(\%)$ & $\chi^{2}$ & $p$-value \\
\hline \multicolumn{6}{|l|}{ Support from family } \\
\hline Strong support & $16(7.8)$ & $188(92.2)$ & $204(100.0)$ & 1.253 & 0.000 \\
\hline Weak support & $49(74.2)$ & $17(25.8)$ & $66(100.0)$ & & \\
\hline Total support from friends & 65 & 205 & 270 & & \\
\hline Strong support & $30(14.6)$ & $175(85.4)$ & $205(100.0)$ & 20.824 & 0.000 \\
\hline Weak support & $26(40.0)$ & $39(60.0)$ & $65(100.0)$ & & \\
\hline Total support from significant others & 56 & 214 & 270 & & \\
\hline Strong support & $55(27.4)$ & $146(72.6)$ & $201(100.0)$ & 92.2 & 0.000 \\
\hline Weak support & $62(89.9)$ & $7(10.1)$ & $69(100.0)$ & & \\
\hline Total & 117 & 153 & 270 & & \\
\hline
\end{tabular}

useful in giving support to patients with knee osteoarthritis by providing emotional, social and financial support. ${ }^{11-16}$

The children of the respondents in this study appeared to be their most important source of social support. This finding is consistent with several studies that have shown that most elderly patients receive support majorly from their children. ${ }^{9,11,20}$

The majority of the respondents earned more than one US dollar per day or 4500 naira (N4 500) per month. This is impressive in a country where $70 \%$ of Nigerians live below one US dollar per day. ${ }^{31}$ This may be a reflection of the financial support enjoyed from their adult children apart from their regular income or pension.

\section{Perceived social support}

Salient observations from this study were that about 7 in 10 of the respondents (69.9\%) who perceived strong support from their families had good health perception. This is noteworthy because a more recent finding by Ogunbode et al. reported that majority of respondents with knee osteoarthritis reported that the presence of the disease affected their self-rated health adversely. ${ }^{6}$ A study on perceived family support of patients with type II diabetes mellitus in University College Hospital, Ibadan in 2007 revealed an inverse relationship between levels of perceived family support and blood glucose control. ${ }^{19}$ Furthermore, there was also a statistically significant association between strong support from friends and good health perception in our study. This finding is supported by previous studies on social support and health outcomes, which have reported that individuals with stronger social relationships had reduced morbidities and mortality. ${ }^{19,20}$

\section{Conclusions}

This study revealed that perceived social support from family members was found to be adequate and this was significantly associated with good health perception and better functional health of respondents. This study confirms the importance of the family structure as source of social support in promoting health. It also highlights the importance of identifying people without a strong social support network. Such people could benefit from alternative sources of practical and psychological support, such as home visits and counselling.

Competing interests - The authors declare that they have no financial or personal relationships that may have inappropriately influenced them in writing this article.
Acknowledgements - Dr Ayo Fayehun, for his assistance in the analysis of the results.

\section{References}

1. Das SK, Farooqi A. Osteoarthritis. Best Practice and Research. Clinical Rheumatology. 2008;22(4):657-75.

2. Hunter DJ, Felson DT. Osteoarthritis Clinical review. BMJ 2006;332:639-42.

3. Cross M, Smith E, Hoy D, et al. The global burden of hip and knee osteoarthritis estimates from the global burden of disease 2010 study. Ann Rheum Dis. 2014;7(2):26-30.

4. Akinpelu OA, Alonge TO, Adekanla BA, Odole AC. Prevalence and pattern of symptomatic knee osteoarthritis in Nigeria: A community based study. The Internet Journal of Allied Health Sciences and Practice. 2009;7(3):1504-80.

5. Dekker J, van Dijk GM, Veenhof C. Risk factors for functional decline in osteoarthritis of the hip or knee. Current opinion in rheumatology 2009 Sep;21(5):520-4.

6. Ogunbode AM, Adebusoye LA, Olowookere OO, Alonge TO. Physical Functionality and Self-Rated Health Status of Adult Patients with Knee Osteoarthritis Presenting in a Primary Care Clinic. Ethiop J Health Sci. 2014 Oct;24(4):319-28.

7. Altman R, Asch E, Bloch D, et al. Development of criteria for the classification and reporting of osteoarthritis. Classification of osteoarthritis of the knee. Diagnostic and Therapeutic Criteria Committee of the American Rheumatism Association. Arthritis \& Rheumatism. 1986;29(8):1039-49.

8. Campbell TL, Bray JH. The Family Influence on health. In: Rakel RE, editor. Principles of Family Practice. 6th ed. Philadelphia, PA: WB Saunders; 2002. p. 34-51.

9. World Health Organization. Statistical Indices of Family Health No. 1976;587.

10. Inem AV, Ayankogbe OO, Obazee M, Ladipo MM, Udonwa NE, Odusote K. Conceptual and contextual paradigm of the family as a unit of care. Nig Med Pract 2004;45(1):9-12.

11. Lee HY, Jang SN, Lee S, Cho SI, Park EO. The relationship between social participation and self-rated health by sex and age: A crosssectional survey. Int J Nurs Stud. 2008 Jul;45(7): 1042-54.

12. Ethgen $O$, Vanparijs $P$, Delhalle $S$, Rosant $S$, Bruyère $O$, Reginster JY. Social support and health-related quality of life in hip and knee osteoarthritis. Qual Life Res 2004;13:321-30.

13. Kiecolt-Glaser JK, Newton T. Marriage and health: his and hers. Psychol Bull. 2001;127(4):472-503.

14. Martire LM, Lustig AP, Schulz R, Miller GE, Helgeson VS. Is It Beneficial to Involve a Family Member? A Meta-Analysis of Psychosocial Interventions for Chronic Illness. Health Psychol 2004;23:599-611.

15. Martire LM, Schulz R, Francis JK, Rudy TE, Starz TW. Couple-Oriented Education and Support Intervention: Effects on Individuals with Osteoarthritis and Their Spouses Rehabilitation Psychology. 2007;52(2):121-32.

16. Holmes AM, Deb P. The effect of chronic illness on the psychological health of family members. J Ment Health Policy Econ. 2003 Mar;6(1):13-22. 
17. Sawatzky R, Liu-Ambrose T, Miller WC, Marra CA. Physical activity as a mediator of the impact of chronic conditions on quality of life in older adults. Health Qual Life Outcomes. 2007;5:68.

18. Keefe FJ, Smith SJ, Buffington ALH, Gibson J, Studts JL, Caldwell DS. Recent advances and future directions in the biopsychosocial assessment and treatment of arthritis. Journal of Consulting and Clinical Psychology. 2002;70:640-55.

19. Adetunji AA, Ladipo MMA, Irabor AE, Adeleye JO. Percieved family support and blood glucose control in type II diabetes. MERA: Diabetes. International 2007;32:18-19.

20. Zhang $X$, Norris S. Social support and mortality among older persons with diabetes. The Diabetes Educator. 2007;33(2):273-81.

21. Zimet GD, Dahlem NM, Zimet SG, Farley GK. The Multidimensional Scale of Perceived Social Support. Journal of Personality Assessment 1988;52(1):30-41.

22. Procidano ME, Heller K. Measures of perceived social support from friends and from family: Three validation studies. Am J Community Psychol 2004;11(1):14-21.

23. Mba CJ. The health condition of older women in Ghana: a case study of Accra city. Journal of International Women's Studies 2006;8(1):171-84.

24. Republic of Nigeria Official Gazette 2007; 24(94): B194-5. [cited 2011 Jun 2]. Available from: http://www.nepza.gov.ng/downloads.

25. Araoye OM. Subject selection. Research methodology with statistics for health and social sciences. Nathadex: Ilorin, Nigeria; 2003. p. 115-29.
26. Jinks C, Jordan K, Ong BN, Croft P. A brief screening tool for knee pain in primary care (KNEST). Results from a survey in the general population aged 50 and over. Rheumatology. 2004;43:55-6.

27. Akinpelu AO, Odole AC, Adegoke BO, Adeniyi AF. Development and Initial validation of the Ibadan Knee/Hip Osteoarthritis Outcome Measure. SA Journal of physiotherapy. 2007;63(2):3-8.

28. Akinpelu AO, Akinwola MO, Odole AC, Gbiri CA. The Reliability of the English version of Ibadan Knee/Hip Osteoarthritis Outcome Measure (IKHOAM) Physical and Occupational Therapy in Geriatrics. 2011. pp. 1-8.

29. Odole AC, Akinpelu AO, BamgboyeEA. Validity and internal consistency of a Yoruba version of the Ibadan Knee/Hip Osteoarthritis Outcome Measure (Yoruba IKHOAM). African J Med Med Sci. 2006; 35:349-57.

30. Stubbs B, Hurley M, Smith T. What are the factors that influence physical activity participation in adults with knee and hip osteoarthritis? A systematic review of physical activity correlates. Clin Rehabil. 2015 Jan;29(1):80-94.

31. United Nations Development Programme. Human Development Report 2006. [Cited 2016 May 10]. Available from: http://wwwhdr. undp.org.report//downloads

Received: 15-11-2015 Accepted: 02-06-2016 